\title{
LEITURA: DA TABULETA DE ARGILA À TELA DOS COMPUTADORES
}

\author{
Eliane Gonçalves Costa Anderi* \\ Mirza Seabra Toschi*
}

\begin{abstract}
RESUMO: Esta reflexão teórica é fruto da pesquisa "Leitura na Tela" que teve como objetivo investigar o modo de leitura nas telas dos computadores que tem acontecido em escolas da rede pública estadual. A leitura na tela tem instigado diversos pesquisadores a refletir sobre suas especificidades, como Chartier que observa que "a cultura do texto eletrônico [é] forçosamente um mundo de telas". Weissberg, por sua vez, acredita que a tela não é mais superfície de projeção ou de recepção, mas é órgão de visão, tornando as imagens sintéticas, com que convivemos, em uma nova escrita e uma nova leitura. Nesta leitura privada, autônoma e protagonista do texto na tela, o leitor pode ser o autor, o editor, o distribuidor de textos escritos por ele e por outro. A linguagem hipermídia, segundo Santaella, se caracteriza por: hibridização de linguagens (sons, imagens fixas/movimento, textos, códigos, signos); organização dos fluxos informacionais em arquiteturas hipertextuais; e por possuir um cartograma navegacional e uma linguagem interativa, o que garante a imersão dos leitores. Santaella identifica três tipos de leitores: o contemplativo, o movente e o imersivo, e três tipos de usuários da Internet: o novato, o leigo e o experto. Além de conhecer, descrever, analisar e interpretar o modo como professores e estudantes da Educação Básica leem na tela, brevemente apresentados aqui, a equipe do estudo também investe na formação dos professores para o uso pedagógico das novas mídias.
\end{abstract}

PALAVRAS-CHAVE: Leitura na tela. Usuários da Internet. Leitura no computador.

A recente história social da leitura no mundo tem apontado mudanças operadas neste campo, envolvendo tanto os leitores quanto os seus gestos de leitura. Trata-se de transformações ainda pouco perceptíveis, mas de radical impacto sobre a subjetividade humana.

Busca-se aqui chamar a atenção para alguns elementos presentes no atual debate, com vistas a compreender, à luz destes, as transformações em curso e suas implicações nos processos de constituição do leitor e da leitura e, como isto influenciará na prática pedagógica dos professores.

\footnotetext{
*Universidade Estadual de Goiás. Imeio: egcanderi@gmail.com.

Universidade Estadual de Goiás. Imeio: mirzas@brturbo.com.
}

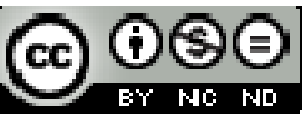

Texto Digital, Florianópolis, v. 8, n. 2, p. 53-67, jul./dez. 2012. ISSNe: 1807-9288 


\section{Vínculo entre os modos de leitura e os suportes da escrita}

Ao inventar a escrita, o ser humano deixou de contar apenas com a tradição oral, passando a armazenar suas histórias, leis e o conhecimento por meio da escrita. Os registros escritos passam a exigir a capacidade de identificar e interpretar os códigos, e com ela, a leitura.

A história da leitura está intimamente ligada às possibilidades que o ser humano criou para ler. Os processos de fixação da escrita vão se transformando ao longo do tempo e caminharam na direção da facilitação, pois saíram de uma tabuleta de argila, para o papiro, para os rolos de pergaminho, para o livro, o disquete, os CD-Roms, telefone celular e os tablets.

A escrita, na Antiguidade, foi colocada a serviço da cultura oral e da conservação do texto. Continha textos escolares, relatos de viagens ou registros contábeis e a sua leitura era feita por um número pequeno de pessoas, as alfabetizadas. Já no período helenístico, a literatura passa a depender da escrita e do livro e Roma herda do mundo grego as práticas de leitura e o suporte do texto era o volumen. Com o surgimento do códex, um livro com páginas, que veio para substituir o livro de rolo a partir do século II DC, surgiram, então, novas práticas de leitura.

Segundo Chartier (1999), o surgimento do códex inaugura uma forma nova de leitura que rompe drasticamente com as práticas de leitura praticadas com o livro de rolo.

No início da era cristã, os leitores dos códex tiveram que se desligar da tradição do livro em rolo. Isso não fora fácil, sem dúvida. A transição foi igualmente difícil, em toda uma parte da Europa do século XVIII, quando foi necessário adaptar-se a uma circulação muito mais efervescente e efêmera do impresso. Esses leitores defrontavam-se com um objeto novo, que Ihes permitia novos pensamentos, mas que ao mesmo tempo, supunha o domínio de uma forma imprevista, implicando técnicas de escrita ou de leitura inéditas. (CHARTIER, 1999, p. 93) 
Entre os séculos XI e XIV, quando renascem as cidades e com elas as escolas, desenvolvendo a alfabetização, surge também uma nova era da história da leitura, pois o livro passa a representar instrumento de trabalho intelectual, de onde se chega ao saber.

Antes da invenção da imprensa, os leitores podiam comprar livros diretamente nos stationarii ${ }^{1}$ ou encomendava ao scriptor ou copista. Os cadernos ${ }^{2}$ (quaderni) eram alugados aos livreiros e o valor a ser cobrado era definido pela universidade. O sistema de cadernos permitia que vários copistas trabalhassem em uma mesma obra simultaneamente. A criação da imprensa suscita grandes mudanças nos modos de ler, com o favorecimento da circulação dos textos que permitiu que cada leitor tivesse acesso a um número maior de livros.

Atualmente, a leitura está presente em praticamente todas as relações sociais dos seres humanos: no mundo do trabalho, nas relações comerciais, nas relações interpessoais. Verifica-se a necessidade de se comunicar com as pessoas que se encontram ausentes, necessitando então que se deixe um bilhete, que se envie um convite, um memorando, um aviso, uma carta, etc. Tudo isto são textos escritos que pressupõem um leitor.

Nas atividades de entretenimento como o cinema, o teatro, o jogo de futebol, uma festa, o vídeo game, tem a presença da leitura e da escrita. Essas práticas fazem com que a leitura e a escrita assumam grande importância nessa sociedade.

A leitura então, se apresenta simultaneamente como uma técnica e como uma prática que não pode se restringir à decodificação dos signos escritos ou aos limites impostos por uma frase, sendo que isto pode contribuir para a ampliação das diferenças sociais existentes entre os que dominam a leitura em todas as suas modalidades e os que não leem com proficiência, pois a falta de domínio da

\footnotetext{
${ }^{1}$ Comerciantes de livro.

${ }^{2}$ Códice adquire forma de livro e é constituído de quaderni (cadernos) os quais possuíam uma quantidade variável de páginas (fólios). Uma mesma obra era formada de vários cadernos.
} 
leitura impede as pessoas de ter uma compreensão crítica da realidade e de ter acesso a níveis mais elaborados de conhecimento.

Ler passou a ser condição básica de existência no mundo contemporâneo e com o advento das Tecnologias da Informação e Comunicação (TIC) torna-se indispensável ler bem, rápido e de forma crítica, ou seja, saber se se pode confiar ou não na informação lida.

Cultura digital é uma expressão que vem sendo empregada para caracterizar o momento correspondente aos processos de digitalização das informações. Ele designa e aponta as várias transformações de caráter cultural, social, político e técnico que envolve a mudança de uma matriz tecnológica para outra.

Moura e Mantovani (2003) afirmam que as alterações ocorridas no suporte material da informação iniciaram o apagamento de um dos critérios que possibilitava distinguir, hierarquizar e classificar os discursos disseminados: o suporte físico. O formato eletrônico relativizou o papel enquanto suporte textual rompendo, assim, com as possibilidades de identificação da informação a partir da forma, passando a exigir novas habilidades tanto para construir os discursos quanto para assimilá-los.

\section{A leitura na tela}

A geração net, ou nativos digitais, na versão de Prenski (2001), não teme o computador e, ao contrário, não sabe conviver sem ele. Os estudantes de hoje, no dizer do autor:

representam a geração que está crescendo com a tecnologia digital. Eles gastam suas vidas jogando jogos de computador, videogames, assistindo TV, celulares etc. Os jovens de hoje gastam, no total, cerca de 5.000 horas de suas vidas lendo e estudando... Porém, passam 10.000 horas de suas vidas jogando videogames. (Nem vou comentar as 20.000 horas que passam assistindo TV). Computadores, celulares, televisores, mensagens instantâneas (MSN) já fazem parte de suas vidas (p. 1). 
Assim, tantos anos convivendo com telas de televisão, de videogames, de computadores, de celulares, de MP4, MP5, MP6... provocaram alterações significativas na forma como estes jovens se relacionam, convivem, estudam e trabalham.

Prensky (2004) observa que:

agora nós temos uma geração que absorve informação melhor e que toma decisões mais rapidamente, são multitarefa $\mathrm{e}$ processam informações em paralelo; uma geração que pensa graficamente ao invés de textualmente, assume a conectividade e está acostumada a ver o mundo através das lentes dos jogos e da diversão (p. 3).

Inúmeros teóricos têm refletido sobre a relação humana com as máquinas digitais, com o computador. Com base em Chartier (1999), Weissberg (2001), Quéau (2001), Castells (2003), Silva (2004), Pais, (2002), Ribeiro, (2006) vamos sintetizar suas ideias em torno do que interessa ao estudo em desenvolvimento, que é a leitura nas telas dos computadores.

Chartier (1999) observa que "a cultura do texto eletrônico [é] forçosamente um mundo de telas" (p.139). Nessa leitura privada, autônoma e protagonista do texto na tela, o leitor pode ser o autor, o editor, o distribuidor de textos escritos por ele e por outrem.

Conforme Weissberg (2001), "a tela não é mais superfície de projeção (cinema), nem de recepção (televisão), tornou-se órgão de visão" (p. 122), mas é o ser humano real que dá existência a esse mundo virtual. $O$ diálogo tem sido a vida do ciberespaço.

Vemos imagens nas telas, sejam elas letras, fotos, filmes. Assim, de acordo com Quéau (2001), está em curso uma revolução escrita profunda que incorpora uma relação entre imagem e linguagem, na qual "o legível pode engendrar o visível" 
(p. 91). Ler na tela, então, é "ver imagens". A letra digitada e que aparece na tela não é mais letra, mas sim imagem de síntese.

Ainda segundo o mesmo autor, enquanto as imagens fotográficas, cinematográficas ou televisuais são linguagens visuais, as imagens infográficas (dos computadores) são imagens de síntese encarnadas abstratamente em modelos matemáticos e em programas de informática. Essa imagem é, sempre, simultaneamente, linguagem e imagem de síntese, que é essencialmente abstrata. Essa é a verdadeira revolução para o autor, que é a capacidade da infografia de dar ao espectador o sentimento de "imersão" interativa na imagem (p. 93). As imagens de síntese têm grande propensão a circular em redes interativas, pois esse tipo de imagem "modifica nossa relação com o real, estruturando-o de outra forma, como instrumento de escrita" (p. 94).

A expansão da Internet inaugurou uma nova era, um momento de transição na comunicação, fez surgir um novo estilo textual - o hipertexto digital ${ }^{3}$ - um outro texto que permeia as comunicações, numa interface com a dinâmica com que flui o processo de comunicabilidade.

O hipertexto digital sinaliza um novo estilo linguístico, um texto aberto, livre, solto, sem fronteiras definidas. Nesta ruptura, com normas fundamentadas na história e na cultura de um povo e implícitas em seus linguajares formal ou coloquial, ele caracteriza-se por uma produção independente e extremamente liberal, mas que não exclui, nem pode excluir outros textos.

Ler um texto em papel é bem diferente de ler um texto na tela, pois embora os dois se apresentem sob a forma escrita, cada tipo de leitura requer um comportamento diferente de cada leitor. O texto impresso em papel é lido palavra por palavra, página por página, enquanto a leitura do texto digital, segundo

3 Hipertexto digital neste trabalho está sendo entendido quando o texto em sua materialidade simula a não linearidade e ocorre no computador. Hipertexto impresso - quando sua materialidade simula a não-linearidade da leitura como processo mental e sua materialidade ocorre no papel. 
estudos de Nielsen (1997), é escaneado, como se fosse uma leitura dinâmica, na qual se pinçam palavras-chave do texto, como se se estivesse imerso nas imagens que representam.

Essa perspectiva imersiva explica um pouco a forma de escrita na tela, com o uso de emotions, diferentes tamanhos, cores e movimentos das letras. Esta tem sido a linguagem mais usada e requerida pelos jovens em sua relação com amigos, como se a escrita na tela assumisse a comunicação oral.

\footnotetext{
Ferramentas para a produção escrita (editores de texto, de páginas web, de histórias em quadrinhos) e para a comunicação à distância (bate-papo, icq e correio eletrônico) inauguram novas condições de produção de discurso integrando elementos originais ao que hoje denominamos leitura - escrita. O hipertexto como gênero de discurso e os emotions como recurso expressivo são bons exemplos de mudanças linguístico-discursivas decorrentes das condições virtuais de produção de enunciados (SILVA, 2003, p. 22).
}

É inegável que a gama de possibilidades de informações instantâneas acelera a motivação da multilinearidade nos nexos e redes em contraposição à linearidade do texto tradicional bem como a facilidade de manipulação e a eficiência possibilitada pela técnica da digitalização que trouxe transformações significativas em diversos setores da vida social, incluindo a cultura, a ciência e a educação.

Para a educação, o desafio é que além da preocupação com o desenvolvimento de sujeitos leitores, faz-se necessário se ater também para os novos processos de leitura requeridos pelo uso das tecnologias da comunicação e informação.

\section{Novo leitor - desafia práticas de leitura da escola}

Mas o que é ler? Para Silva (2000, apud PAN; VILARINHO, 2005), "o ato de ler envolve apreensão, apropriação e transformação de significados, a partir de um documento escrito" (p. 1). 
Sendo assim, ler não se reduz à decifração de códigos, é muito mais do que isso, é, principalmente, saber estabelecer conexões e também é:

uma atividade interativa altamente complexa de produção de sentidos, que se realiza evidentemente com base nos elementos linguísticos presentes na superfície textual e na sua forma de organização, mas requer a mobilização de um vasto conjunto de saberes no interior do evento comunicativo (KOCH; ELIAS, 2006, p. 11).

A leitura de um texto exige que o leitor saiba muito mais que somente 0 conhecimento linguístico compartilhado pelos interlocutores. Ao ler ele mobiliza uma série de estratégias de ordem linguística e de ordem cognitivo-discursiva que o possibilita levantar hipóteses, validar ou não as hipóteses formuladas, preencher as lacunas que o texto apresenta, participando ativamente da construção do sentido. Nesse processo, autor e leitor devem ser vistos como estrategistas na interação pela linguagem.

Os leitores reconhecem que o significado do texto a ser construído depende tanto dos objetivos e das perguntas do leitor como da natureza do texto e de sua macro superestrutura. Além disso, é importante e necessário que as pessoas aprendam a usar as estratégias de leitura como faz um leitor maduro, a fim de que se torne também um leitor eficiente e autônomo.

Deste modo, torna-se premente a necessidade de a escola assumir a leitura como um processo de interação entre autor-texto-leitor no qual interferem, entre outros aspectos, a situação cultural, política e social de cada leitor e as suas relações intertextuais. Assim, o papel do leitor torna-se cada vez mais decisivo, tanto na leitura analógica quanto na digital.

Para Silva (2003, p. 13), a leitura concretiza um papel socializante na medida em que permite ao sujeito o domínio de competências "capazes de possibilitar práticas de leitura e de letramento contínuo, aqui entendidas como atividades estruturantes do pensamento-linguagem, do conhecimento e da cultura". 
Parece pertinente afirmar que ler é mergulhar nas malhas da rede, é perder-se, é libertar-se; a linearidade dá lugar ao hipertextual, ao móvel e flexível, à interatividade que permite conectar temas e ideias em duplo sentido: escolher links e produzir inferências (CORREIA; ANTONY, 2003 apud PAN; VILARINHO, 2005, p. 2)

Moura e Montovani (2003) defendem que navegar por um texto não se restringe tão somente ao suporte digital, mas trata-se do percurso que o leitor pode fazer em determinado objeto de leitura seja ele um texto, um gráfico, um sumário, um índice ou uma legenda. O que conta são suas escolhas, o caminho que irá percorrer. Trata-se de uma reconfiguração das práticas de leitura e das formas de produção e publicação de textos. A novidade está no próprio suporte e na velocidade com que os nós são acessados nos hipertextos digitais.

Na compreensão de Santaella (2004), a linguagem hipermídia tem quatro traços caracterizadores que garante a imersão dos leitores que são:

a) a hibridização de linguagens (sons, imagens fixas e em movimento, textos, códigos, signos) - é o acionamento integrado de textos aos processos sígnicos, códigos e mídias sem qualquer sutura em um único ambiente;

b) a organização dos fluxos informacionais em arquiteturas hipertextuais - é a capacidade de armazenamento de informações que, por meio da interação, o sujeito consegue alterar, transformar, converter ou disfarçar incontáveis versões de um texto virtual, online, que brota na medida em que o sujeito se coloca na posição de co-autor. Isto só é possível de acontecer em função das características de não linearidade do hiper,

c) um cartograma navegacional - para transitar pelas infovias o internauta necessita se orientar na rede sob pena de se frustrar ao não conseguir ajustar os alvos pretendidos, por isso fez-se necessário a criação de mapas para a navegação que são os portais que permitem a seleção de conteúdos; os programas de busca na www; os programas de filtro que 
permite aos pais programar seus computadores de acordo com aquilo que julgam ser ou não conveniente ser acessado pelos filhos e os $C D$-Roms que trazem os mapas de navegação;

d) e uma linguagem interativa - que é a combinação da inseparabilidade do caráter hipertextual, hipermidiático de sua linguagem com a interatividade e a autonomia do internauta em determinar qual é a informação que deseja ou não acessar e em qual sequência.

Nas escolas, cuja base é a escrita em papel, esse debate é urgente e os professores merecem participar dessa reflexão. Os jovens que estão atualmente na Educação Básica demonstram possuir grande potencial de compreensão da nova linguagem que se apresenta na rede, que é a hipermídia.

Não se conseguirá a atenção de um jovem ou criança, em uma escola que só faz uso tão somente da oratória, leitura e escrita. Eles já conhecem outros meios mais atrativos de aprender. "Assistir" a um programa de TV é, muitas vezes, bem melhor do que "assistir" a um professor. Não se está afirmando que as mídias podem substituir o papel exercido pelo professor, mas podem modificar a forma pela qual se vê o mundo. Como a cultura da imagem é uma característica forte das novas gerações, ela pode ser explorada pedagogicamente na escola, pois as notícias, as novidades do planeta estão expostas a todo o momento pela televisão e na Internet. Todavia, a forma de organização da escola e dos processos de ensino/aprendizagem se coloca como barreira para um uso mais adequado dessas ferramentas com potencialidades educativas.

A escola pouco explora, por exemplo, o valor informativo, implícito e/ou explícito, e a qualidade atrativa da TV como veículo da cultura imagística. Com a introdução da informática, do computador e da Internet na sala de aula, é preciso um policiamento para que não se caia no mesmo erro, achando que o simples uso do equipamento, independentemente dos objetivos traçados, já faz a diferença pedagógica. 
Com a Internet, as pessoas são desafiadas a executar um novo tipo de leitura, na qual as informações se apresentam como uma rede de nós, "interconectados por links, que podem ser acessados livremente" (RAMAL, 2002 apud PAN; VILARINHO, 2005, p. 1).

Observa Santaella (2004) que a formação de redes é prática humana antiga e avalia que atualmente as redes ganharam vida nova - energizadas pela Internet e isso interfere no significado da mensagem.

Castells (2003) diz também que, apesar das vantagens da sua flexibilidade, as redes entram em conflito com as hierarquias centralizadas por permitirem decisão coordenada e execução descentralizada. A liberdade individual e a comunicação aberta tornaram-se valores supremos, o que entra em choque com as orientações coletivas e hierárquicas como as existentes nas escolas.

Santaella (2004), na obra "Navegar no ciberespaço - o perfil cognitivo do leitor imersivo", enumera três tipos de leitores: o contemplativo, o movente e o imersivo. Enquanto o primeiro refere-se ao leitor meditativo, silencioso, de obras escritas em livros, o leitor movente é aquele fragmentado, que habita o cenário volátil da cidade, cheia de imagens, fotos, outdoors. Já o leitor imersivo, é aquele "implodido cuja subjetividade se mescla na hipersubjetividade de infinitos textos num grande caleidoscópio tridimensional” (p. 33). Continua a autora dizendo que

\footnotetext{
a navegação interativa entre nós e nexos pelos roteiros alineares do ciberespaço envolve transformações sensórias, perceptivas e cognitivas que trazem consequências também para a formação de um novo tipo de sensibilidade corporal, física e mental (SANTAELLA, 2004, p. 34).
}

As mídias móveis, como os celulares e os tablets, sugerem o aparecimento do leitor ubíquo, que lê a qualquer hora e em qualquer lugar.

A autora faz referência também a três tipos de usuários: o novato, o leigo e o experto. $\mathrm{O}$ experto é aquele que encontra o que deseja com grande facilidade. 
Conhece a estrutura da rede, não se perde, não hesita, conhece o uso do clique direito do mouse e articula, com presteza, o controle sobre o mouse e o teclado, do olhar sobre a tela e o conhecimento do mapa da rede. O leigo não tem muita familiaridade com o ambiente da Internet, fica perdido, mas tem algum conhecimento de como se faz buscas nela. O novato, por sua vez, não compreende a estrutura da rede e, por isso, faz uso limitado dela. Identificamos no estudo que há alunos no nível de experto e os professores estão entre o novato e o leigo.

A preocupação básica do professor, atualmente, é com as formas de explorar as potencialidades desses meios de comunicação informatizados no ambiente educacional, especificamente o computador. Preocupação legítima, uma vez que a grande maioria não tem apropriação tecnológica. Isso ficou evidente no estudo. Descobrir como incorporar as possibilidades que a Internet e o computador oferecem à sala de aula é um desafio. Renovando a forma como a pesquisa tem sido praticada na escola; o caráter comunicativo da Internet altera totalmente esse processo de descoberta.

Com seu emprego, o estudante se mantém em contato direto com os meios de comunicação da sociedade. Ao estar conectado ao mundo, ele tem acesso a quase tudo o que se produz, seja de cunho científico ou não, no planeta e a tudo que está disponibilizado na rede mundial de computadores.

A possibilidade que a internet nos abre para subverter os aparatos do poder, pois ali não existe controle da comunicação, nem de governos, nem de empresas, nem de instituições educacionais. No mundo virtual, a comunicação falada, escrita e/ou lida é horizontal, livre e democrática: talvez resida nisso a possibilidade maior de instauração de um certo tipo de cultura entre os homens que, pelas práticas de leitura - aqui tomadas como atividade estruturante do pensamento - poderão, de agora em diante, viver mais intensamente a criatividade e a liberdade (SILVA, 2003, p. 16).

A Internet é um campo vasto e riquíssimo, pode-se utilizá-la como instrumento de comunicação, de pesquisa, de produção de conhecimento, utilizando sua 
interface ideográfica, característica das linguagens simbólicas. No computador apresentam-se por meio de ícones, signos que simbolizam, de forma gráfica, objetos ou conceitos representados por uma determinada imagem. Voltar-se-ia, assim, a ter, na escola, um ambiente rico de informações, de assuntos históricos, atuais, atrativos, com capacidade de atender ao anseio natural que todo ser humano possui de buscar o novo.

\begin{abstract}
O trabalho da escola pode viabilizar a entrada de mais interlocutores na Rede, tanto na função de escritores quanto na de leitores, coautores e aprendizes das maneiras dinâmicas de lidar com textos, calibrando cada vez melhor as atualizações de sentido e a leitura crítica, a triagem de informações e a seletividade, na era do zaper, ainda que ela nos pareça apenas mais uma boa oportunidade de fazer o que o leitor e o escritor sempre fizeram nos modos unplugeed de ler e escrever (RIBEIRO, 2006, p. 30 e 31).
\end{abstract}

Pais (2002) afirma que a prática docente que está essencialmente associada à natureza das ações realizadas pelos estudantes, sofre uma ampliação impulsionada pelo computador e pela Internet. Tem-se assim que as ações didáticas estão sendo condicionadas pelo uso desse novo suporte e necessitam ser redimensionadas, pois as respostas tradicionais não são suficientes para responder aos novos desafios que estão sendo colocados à ação didática.

\begin{abstract}
A construção das competências objetivadas para a formação do aluno depende também da disponibilidade do professor de se engajar na redefinição de sua própria prática, incorporando a ela a componente tecnológica no processo de sua própria formação. Para isso, é preciso que a iniciativa individual de cada um seja exercida em sintonia com a capacidade de participar ativamente em propostas de trabalho coletivo (PAIS, 2002, p. 14).
\end{abstract}

É inegável que os recursos tecnológicos digitais redimensionaram as condições de acesso às fontes de informação e ampliaram as situações de aprendizagem, mas também redimensionam os problemas da escola, pois elas, por si só, não resolvem os antigos problemas de acesso à escola, ao conhecimento e ao exercício da cidadania. Para que se possa beneficiar de todo este aparato, mais do que nunca, é necessário repensar as formas de ensinar e de aprender, 
portanto, é necessário redimensionar a formação e condições de trabalho dos professores, a organização escolar, o currículo, a sala de aula.

\author{
READING: OF THE CLAY TABLET TO THE SCREEN OF COMPUTERS
}

\begin{abstract}
This is the result of theorical research "Reading on Screen" wich the aimed to investigate how read on the screens computers that happened in public schools of the state. The screen reader has instigated several researchers to reflect on their specificities, as Chartier notes that "the culture of the electronic text is necessarily a world of screens. Weissberg, instead, believes that the screen is no longer projection surface or reception, but is an organ of vision, making synthetic images with that we live in a new script and a new reading. In this reading, autonomous and protagonist of the screen text, the reader can be author publisher, distributor of texts written by him and others. The hypermedia language, according Santaella, characterized by: hybridization language (sounds, texts, codes); organization of information flows in hypertext architectures; has an interactive navigational, which ensures the immersing for the readers. Santaella identifies three types of readers: the contemplative, the moving and the immersive. And three types of users of internet: the novice, the expert and the layman. Besides describe, analyze and interpret how teachers and students of basic education read on screen, the study team also invests in the training of teachers for the pedagogical use of the new media.
\end{abstract}

KEYWORDS: Reading on screen. Users of the internet. Reading on the computer.

\title{
Referências
}

CASTELLS, Manuel. A Galáxia da Internet - reflexões sobre a Internet, os negócios e a sociedade. Rio de Janeiro: Jorge Zahar, 2003.

CHARTIER, Roger. A aventura do livro - do leitor ao navegador. Tradução de Reginaldo de Moraes. São Paulo: Unesp, 1999.

$\mathrm{KOCH}$, Ingedore V.; ELIAS, Vanda Maria. Ler e Compreender os sentidos do texto. São Paulo: Contexto, 2006.

MOURA, Maria Aparecida; MANTOVANI, Flávia Fontes. Ler e navegar: reflexões sobre o leitor e a leitura no contexto digital. 2003. Disponível em: <www.alb.com.br/anais14/Sem06/C06034.doc $>$. Acesso em: 10 jul. 2009.

NIELSEN, Jakob. How users read on the web. Disponível em: $<$ http://www.useit.com/alertbox/9710a.html>. Acesso em: 30 jul. 2009.

PAIS, Luiz Carlos. Educação escolar e as tecnologias da informação. Belo Horizonte: Autêntica, 2002.

PAN, Maria Claudia de O.; VILARINHO, Lúcia R. Goulart. A leitura com uso de suportes virtuais: uma nova questão didática. 2005. Disponível em: 
$<$ http://www.anped.org.br/reunioes/28/textos/gt04/GT04-364--Int.rtf >. Acesso em 07 set. 2008.

PRENSKY, Marc. Digital Natives, Digital Immigrants. In: From On the Horizon, vol. 9, N. 5. NCB University Press, 2001). Disponível em: $<$ http://www.ritla.net/index.php?option=com content\&task=view\&id=1455\&ltemid= 136>. Acesso em: setembro de 2007.

PRENSKY, Marc. Use Their Tools! Speak Their Language!. 2004. Disponível em: <http://www.marcprensky.com/writing/Prensky->. Acesso em: 26 set. 2008.

QUÉAU, Philippe. O tempo do virtual. In: PARENTE, André (org.). Imagem máquina - a era das tecnologias do virtual. Rio de Janeiro: Ed. 34, 2001.

RIBEIRO, Ana Elisa. Texto e leitura hipertextual: novos produtos, velhos processos. In: Revista Linguagem \& Ensino. vol. 9, n. 2, 2006. Disponível em: $<$ http://rle.ucpel.tche.br/index.php?sCentro=php/inicial.php $>$. Acesso em: 10 jul. 2009.

SANTAELLA, Lucia. Navegar no ciberespaço - o perfil cognitivo do leitor imersivo. São Paulo: Paulus, 2004.

Culturas e artes do pós-humano - da cultura das mídias à cibercultura. São Paulo: Paulus, 2003.

SILVA, E. T. Leitura no mundo virtual: alguns problemas. In: SILVA, E. T; et al (coord.). Leitura nos oceanos da internet. São Paulo: Cortez, 2003.

WEISSBERG, Jean-Louis. Real e virtual. In: PARENTE, André (org.). Imagem máquina - a era das tecnologias do virtual. Rio de Janeiro: Ed. 34, 2001.

Texto recebido em 31/10/2012. 